NASA/TM-2005-213592

\title{
NASA Icing Remote Sensing System Comparisons From AIRS II
}

Andrew L. Reehorst, David J. Brinker, and Thomas P. Ratvasky Glenn Research Center, Cleveland, Ohio 
Since its founding, NASA has been dedicated to the advancement of aeronautics and space science. The NASA Scientific and Technical Information (STI) Program Office plays a key part in helping NASA maintain this important role.

The NASA STI Program Office is operated by Langley Research Center, the Lead Center for NASA's scientific and technical information. The NASA STI Program Office provides access to the NASA STI Database, the largest collection of aeronautical and space science STI in the world. The Program Office is also NASA's institutional mechanism for disseminating the results of its research and development activities. These results are published by NASA in the NASA STI Report Series, which includes the following report types:

- $\quad$ TECHNICAL PUBLICATION. Reports of completed research or a major significant phase of research that present the results of NASA programs and include extensive data or theoretical analysis. Includes compilations of significant scientific and technical data and information deemed to be of continuing reference value. NASA's counterpart of peerreviewed formal professional papers but has less stringent limitations on manuscript length and extent of graphic presentations.

- TECHNICAL MEMORANDUM. Scientific and technical findings that are preliminary or of specialized interest, e.g., quick release reports, working papers, and bibliographies that contain minimal annotation. Does not contain extensive analysis.

- CONTRACTOR REPORT. Scientific and technical findings by NASA-sponsored contractors and grantees.
- CONFERENCE PUBLICATION. Collected papers from scientific and technical conferences, symposia, seminars, or other meetings sponsored or cosponsored by NASA.

- SPECIAL PUBLICATION. Scientific, technical, or historical information from NASA programs, projects, and missions, often concerned with subjects having substantial public interest.

- TECHNICAL TRANSLATION. Englishlanguage translations of foreign scientific and technical material pertinent to NASA's mission.

Specialized services that complement the STI Program Office's diverse offerings include creating custom thesauri, building customized databases, organizing and publishing research results ... even providing videos.

For more information about the NASA STI Program Office, see the following:

- Access the NASA STI Program Home Page at http://www.sti.nasa.gov

- E-mail your question via the Internet to help@sti.nasa.gov

- Fax your question to the NASA Access Help Desk at 301-621-0134

- Telephone the NASA Access Help Desk at 301-621-0390

- Write to:

NASA Access Help Desk

NASA Center for AeroSpace Information 7121 Standard Drive

Hanover, MD 21076 
NASA/TM-2005-213592

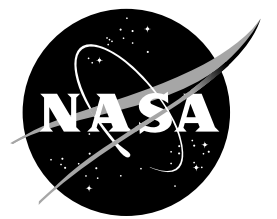

NASA Icing Remote Sensing System Comparisons From AIRS II

Andrew L. Reehorst, David J. Brinker, and Thomas P. Ratvasky Glenn Research Center, Cleveland, Ohio

Prepared for the

43rd Aerospace Sciences Meeting and Exhibit

sponsored by the American Institute of Aeronautics and Astronautics Reno, Nevada, January 10-13, 2005

National Aeronautics and

Space Administration

Glenn Research Center 
Trade names or manufacturers' names are used in this report for identification only. This usage does not constitute an official endorsement, either expressed or implied, by the National Aeronautics and Space Administration.

Available from

NASA Center for Aerospace Information 7121 Standard Drive

Hanover, MD 21076
National Technical Information Service 5285 Port Royal Road Springfield, VA 22100

Available electronically at http:/ /gltrs.grc.nasa.gov 


\title{
NASA Icing Remote Sensing System Comparisons From AIRS II
}

\author{
Andrew L. Reehorst, David J. Brinker, and Thomas P. Ratvasky \\ National Aeronautics and Space Administration \\ Glenn Research Center \\ Cleveland, Ohio 44135
}

\begin{abstract}
NASA has an on-going activity to develop remote sensing technologies for the detection and measurement of icing conditions aloft. A multiple instrument approach is the current emphasis of this activity. Utilizing radar, radiometry, and lidar, a region of supercooled liquid is identified. If the liquid water content (LWC) is sufficiently high, then the region of supercooled liquid cloud is flagged as being an aviation hazard. The instruments utilized for the current effort are an X-band vertical staring radar, a radiometer that measures twelve frequencies between 22 and $59 \mathrm{GHz}$, and a lidar ceilometer. The radar data determine cloud boundaries, the radiometer determines the sub-freezing temperature heights and total liquid water content, and the ceilometer refines the lower cloud boundary. Data is post-processed with a LabVIEW program with a resultant supercooled LWC profile and aircraft hazard identification. Individual remotely sensed measurements gathered during the 2003-2004 Alliance Icing Research Study (AIRS II) were compared to aircraft in-situ measurements. Comparisons between the remote sensing system's fused icing product and in-situ measurements from the research aircraft are reviewed here. While there are areas where improvement can be made, the cases examined indicate that the fused sensor remote sensing technique appears to be a valid approach.
\end{abstract}

\section{Introduction}

\section{A. NASA Icing Remote Sensing System (NIRSS)}

The NASA Icing Remote Sensing System (NIRSS) has been under definition and development at NASA Glenn Research Center since 1997. The goal of this development activity is to produce and demonstrate the required sensing technologies required to accurately remotely detect and measure icing conditions aloft.

The NASA Icing Remote Sensing System is made up of three sensor components, a radar, a microwave radiometer, and a ceilometer (a thorough description of the system is provided in Ref. 1). The radar unit used for the NASA Icing Remote Sensing System for the winter of 2003-2004 was a modified Honeywell WU-870 airborne X-band radar. This radar system is described in detail in Ref. 2. The radar provides reflectivity measurements that are used to define cloud boundaries. The microwave radiometer is a Radiometrics, Inc. TP/WVP 3000 Temperature and Water Vapor Profiler. Among other measurements, this microwave radiometer provides temperature profile and integrated liquid water measurements. Finally, the ceilometer being used is a standard Vaisala CT25K Laser Ceilometer. The ceilometer is used to refine the definition of the lower cloud boundary since it is less susceptible to precipitation for this than is radar. Figure 1 shows these major components of the system as operated during the Alliance Icing Research Study 2003-2004 field program (AIRS II). 


\section{B. NASA Twin Otter Aircraft}

The icing research aircraft is a modified DeHavilland DHC-6 Twin Otter and is shown in Fig. 2. It is a twin-engine commuter type aircraft powered by two 550 shaft horsepower turboprop engines. It has been modified for sustained flight in icing environments and to permit the acquisition of icing data.

The Twin Otter Icing Research Aircraft is equipped with standard flight instrumentation and with instrumentation specific to icing research. The measured flight data consisted of airspeed, outside air temperature, angle of attack, angle of sideslip, droplet size spectra, liquid water content, and altitude. Droplet size was measured with a Forward Scattering Spectrometry Probe (FSSP-100 extended) and an Optical Array Probe (OAP-2DC-Gray). Liquid water content was measured with a CSIRO King probe and a Nevzorov LWC/TWC probe. A Rosemount ice detector (model 871FA211) was used for defining periods of ice accretion. The outside air temperature was measured with a Rosemount model 102AU1P probe. Dew point was measured with a General Eastern Dewpoint Hygrometer. All data was acquired using a Science Engineering and Associates (SEA) M300 data acquisition system. More details of the instrumentation used during this test are included in Ref. 1.

\section{Alliance Icing Research Study 2003-1004 field project (AIRS II)}

The NASA Icing Remote Sensing System and the NASA Twin Otter were operated as part of the Second Alliance Icing Research Study (AIRS II), which was conducted between November 2003 and February 2004. AIRS II was a collaborative scientific project involving numerous research organizations from Canada, the United States and Europe. The central research theme of AIRS II was aircraft icing, with operational objectives to test and evaluate remote sensing technologies, improving icing forecast technologies, further characterize the icing environment, and further characterize the aerodynamic effects of ice accretions.

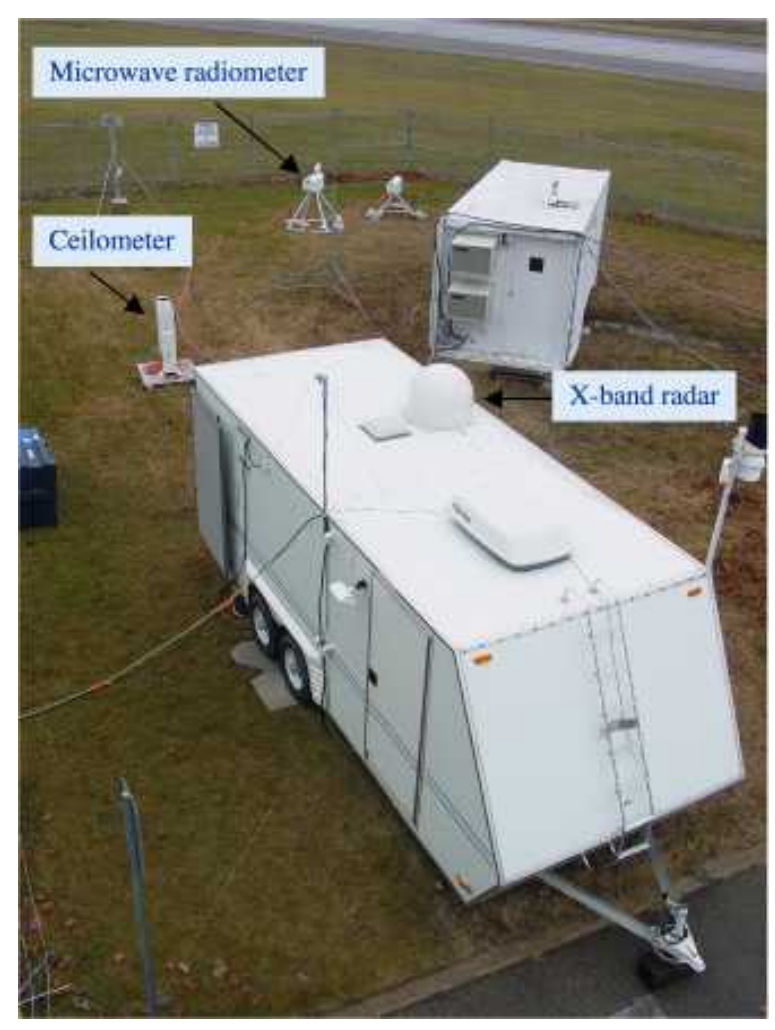

Figure 1. Major components of the NIRSS as deployed to AIRS II.

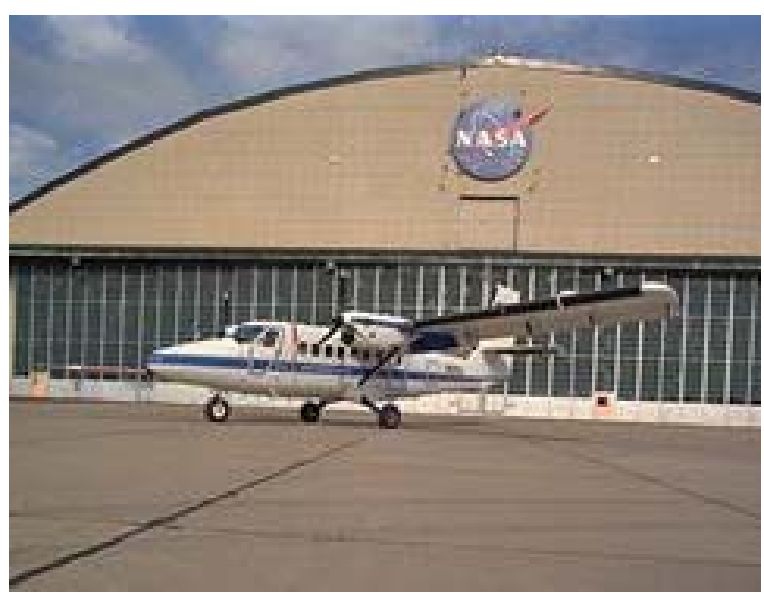

Figure 2. NASA Twin Otter Icing Research Aircraft.

Several research aircraft operated out of Ottawa, Ontario, Cleveland, Ohio, and Bangor, Maine. A large array of instrumentation was located at Mirabel Airport, Montreal, Quebec. The NASA Twin Otter Icing Research Aircraft operated out of Ottawa during the test period. Besides other research activities, the Twin Otter performed spiral descents and missed approaches to obtain atmospheric soundings to compare to ground instrumentation. The NASA Icing Remote Sensing System operated at the Mirabel "Teksol” site. 
Detailed descriptions of the participants, facilities, and flight maneuvers involved with AIRS II are available in Ref. 3.

\section{Data Comparisons}

\section{A. Comparisons of Radiometer to Twin Otter data}

Comparisons were made for all cases between the profiling radiometer and the aircraft for times when the NASA Twin Otter performed descending spirals over the Mirabel site. Flight data over Mirabel was obtained on 11 November 2003 between 1630 UTC and 1657 UTC, 18 November 2003 between 1233 UTC and 1246 UTC, 25 November 2003 between 1809 UTC and 1830 UTC, 10 December 2003 between 1617 UTC and 1637 UTC, and on 10 December 2003 between 1720 UTC and 1732 UTC. It should be noted that the radiometer measurements to be compared here are from the beginning of these aircraft maneuver times.

The Radiometrics Vizmet graphics visualization program was used for these comparisons. This program was designed to plot profiling radiometer data against radiosonde data. The author converted the Twin Otter data to radiosonde format and this data was ingested by Vizmet to generate the comparison plots. Because of the way the data was ingested by Vizmet, the radiometer data is plotted in blue with the MP label and the aircraft data is plotted in red with the RAOB(PRF) label. Three plots are shown for each comparison between flight and remotely sensed data. The left-most plot is the temperature versus altitude, the center plot is the relative humidity versus altitude, and the right-most plot is liquid water content versus altitude.

Besides the display of the two data sources, Vizmet can also perform additional processing of the radiometer data. In the cases presented here, Vizmet performed this additional processing to refine the liquid water profile by ignoring the radiometer's infrared ceiling measurement, requiring the lower cloud boundary to have at least 80 percent relative humidity, requiring the upper cloud boundary to have at least 70 percent relative humidity, and limiting the liquid cloud to warmer than $253 \mathrm{~K}$. These values seem to be reasonable and provided the best agreement over the range of conditions measured during AIRS II.

Data comparison for 11 November 2003, 16301657 UTC

Flight records noted that there was no ice accretion during this spiral maneuver, with only ice crystals present above the freezing level.

The comparison between aircraft measurements and the radiometer is shown in Fig. 3. The air temperature measurements agree within $3 \mathrm{~K}$. The radiometer captured the general shape of the relative humidity profile, but missed much of the detail. Flight measurements of liquid water content are negligible, while the radiometer was measuring peak values above $0.1 \mathrm{~g} / \mathrm{m}^{3}$.

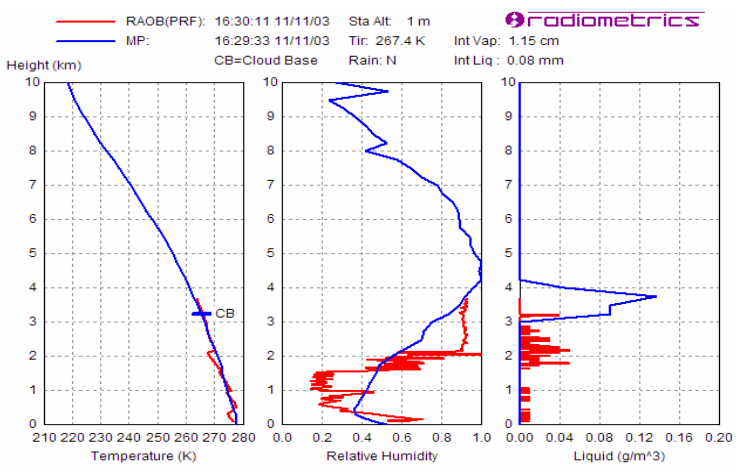

Figure 3. Comparison of TP/WVP 3000 (blue MP) to Twin Otter data (red - RAOB PRF) for 11 November 2003 flight. 
Data comparison for 18 November 2003, 1233-1246 UTC

The flight records noted that there was no ice accretion during this spiral maneuver, with a single cloud layer and clear sky above. In this case there was liquid water present, but the temperatures were above freezing throughout the cloud layer.

The comparison between aircraft measurements and the radiometer is shown in Fig. 4. Likely because of the temperature inversions present, the temperature agreement was not as good for this case (up to $5 \mathrm{~K}$ ) compared to the one shown in Fig. 3. The radiometer underrepresented the relative humidity, did not recognize the presence of the liquid water layer, and distributed low amounts of LWC over the lowest $4 \mathrm{~km}$ of the atmosphere.

Data comparison for 25 November 2003, 1809-1830 UTC

Flight records noted that there was light rime icing during this spiral maneuver with ice crystals precipitating from the cloud and clear sky above the single cloud layer.

The comparison between aircraft measurements and the radiometer is shown in Fig. 5. Again, the remotely measured temperature profile is smoothed through the temperature inversion, resulting in a disagreement of $6 \mathrm{~K}$. The radiometer captured the proper shape of the aircraft measured relative humidity profile, again smoothing through the sharper features. In this case the radiometer did quite well in capturing the location and peak magnitude of the liquid water layer, though the actual liquid layer was roughly one third as deep.

\section{Data comparison for 10 December 2003, 1617-1637 UTC (flight \#1)}

Flight records noted three liquid cloud layers, with the upper one below $0{ }^{\circ} \mathrm{C}$ and producing a light clear ice accretion; the sky was clear above these three layers and clear below the layers with no precipitation observed.

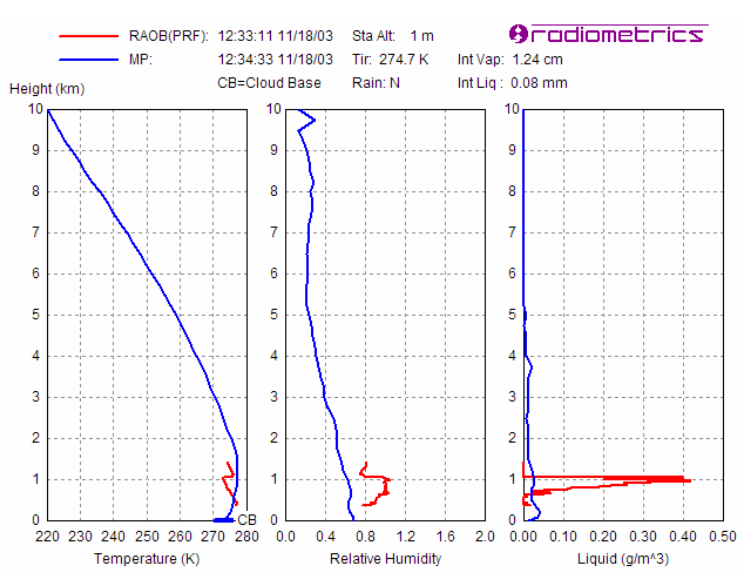

Figure 4. Comparison of TP/WVP 3000 (blue-MP) to Twin Otter data (red - RAOB PRF) for 18 November 2003 flight.

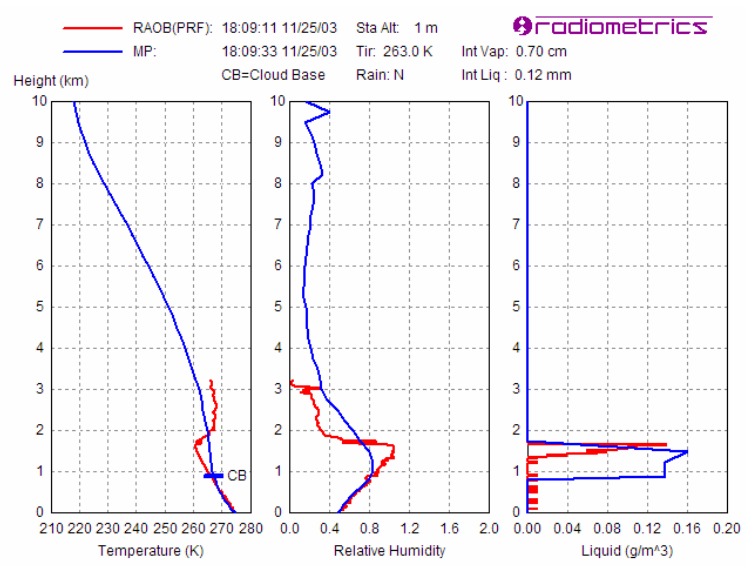

Figure 5. Comparison of TP/WVP 3000 (blue - MP) to Twin Otter data (red - RAOB PRF) for 25 November 2003 flight.

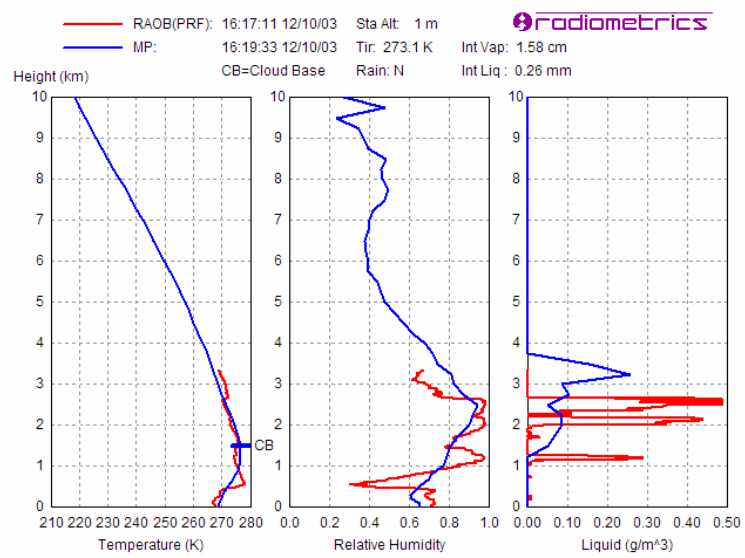

Figure 6. Comparison of TP/WVP 3000 (blue - MP) to Twin Otter data (red - RAOB PRF) for 10 December 2003, flight\#1. 
The comparison between aircraft measurements and the radiometer is shown in Fig. 6. Because of the sharp temperature inversion near 2,000 $\mathrm{ft}(610 \mathrm{~m})$ the disagreement in temperature peaked at that point at $5 \mathrm{~K}$. Again the radiometer does a reasonable job of capturing the large scale shape of the humidity profile measured by the aircraft while smoothing through the finer scale details. Because of this smoothing, the liquid water profile from the radiometer misses the detail required to define the individual layers. In this case it appears qualitatively that the overall water content from the radiometer is close to that of the aircraft measurements, but because of it is distributed over a greater depth, the maximum value is too low.

\section{Data comparison for 10 December 2003, 1720-1732 UTC (flight \#2)}

Occurring roughly an hour after the previous case, flight records again noted three liquid cloud layers, with the upper one colder than $0^{\circ} \mathrm{C}$ and producing a light clear ice accretion; the sky was clear above these three layers and clear below the layers with no precipitation observed.

The comparison between aircraft measurements and the radiometer is shown in Fig. 7. The radiometer's temperature agrees quite well with the aircraft measured values, this time within $4 \mathrm{~K}$. The relative humidity measurements are close, with the radiometer smoothing some rapid changes that the aircraft was able to measure. Again the radiometer bounded the region of aircraft measured liquid water conservatively and missed the layering.

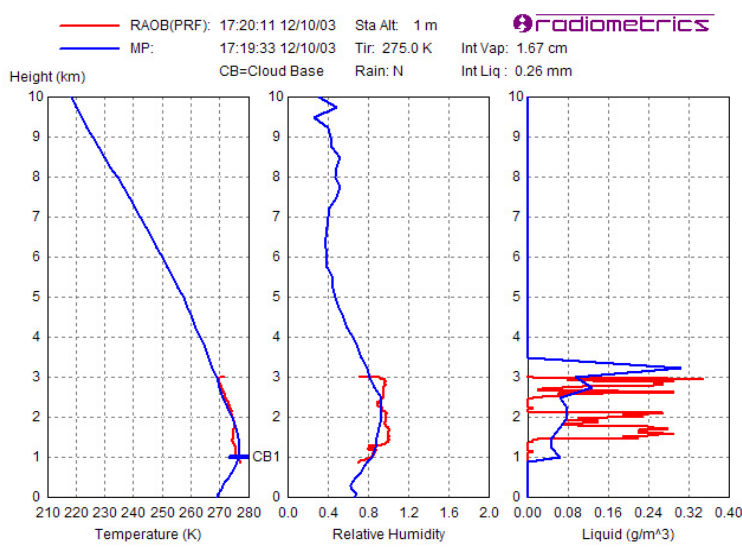

Figure 7. Comparison of TP/WVP 3000 (blue - MP) to Twin Otter data (red - RAOB PRF) for 10 December 2003, flight\#2.

\section{$\underline{\text { Time histories }}$}

While the radiometer does have limitations, particularly in how its profiles are smoothed through rapid temperature and humidity changes, its major strength is that it can operate continuously. Figure 8 through 11 provide the time histories of the conditions over Mirabel airport for the hours before the research flights described above.

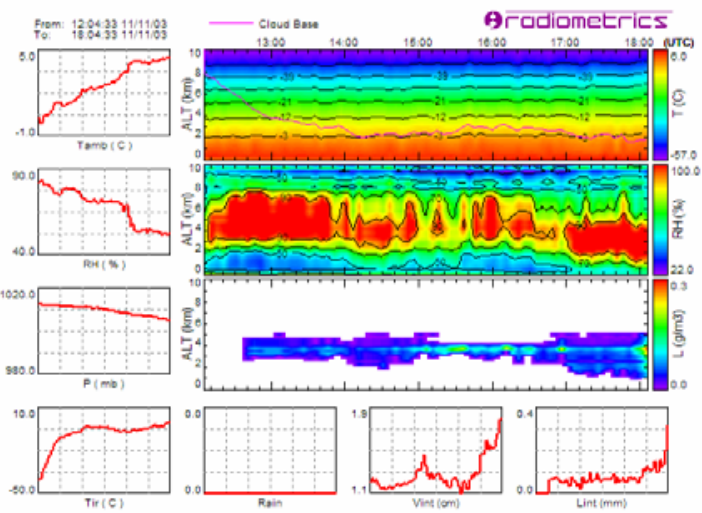

Figure 8. Time history of TP/WVP 3000 retrievals for 11 November 2003, 1204-1804 UTC.

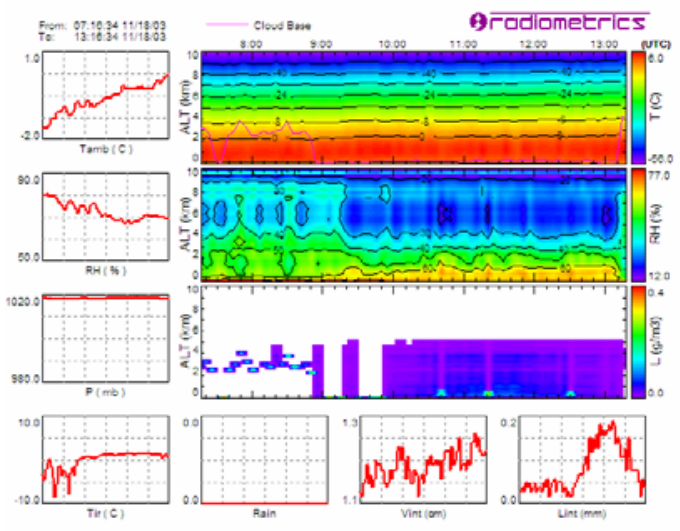

Figure 9. Time history of TP/WVP 3000 retrievals for 18 November 2003, 0716-1316 UTC. 


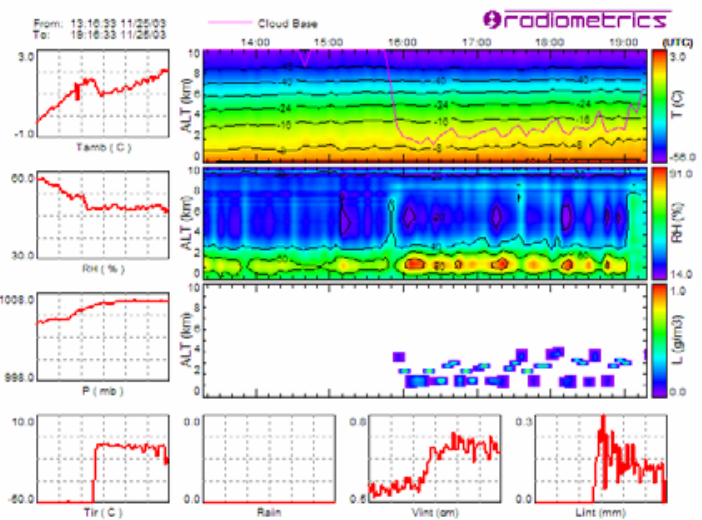

Figure 10. Time history of TP/WVP 3000 retrievals for 25 November 2003 , 1316-1916 UTC.

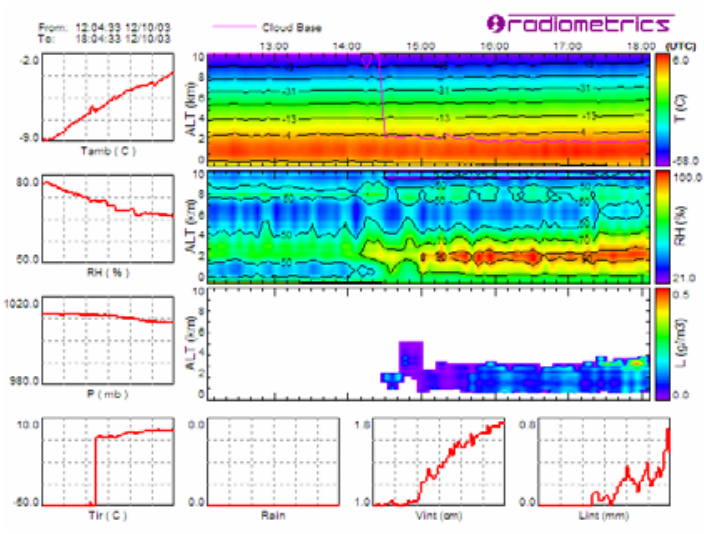

Figure 11. Time history of TP/WVP 3000 retrievals for 10 December 2003, 1204-1804 UTC.

The ability to track the progression of these measurements over time is seen to be of incredible value both for diagnosing current conditions and analyzing past events.

\section{B. Comparison of remotely sensed icing parameters to aircraft data}

Because of the limitations of the profiling radiometer, the NASA Icing Remote Sensing System adds radar and lidar measurements to attempt to refine the vertical distribution of cloud and therefore the liquid water as defined by the radiometer. The data from the X-band radar and the lidar ceilometer described above are processed with the radiometer data to provide more resolved information of the state of the environment above the sensor site. A thorough discussion of the processing technique is included in Ref. 1. The output graphic from the first generation (Gen 1) of the fusion software of the NASA Icing Remote Sensing System is shown in Fig. 12. The fields shown on this graphic include a temperature profile history (top left), cloud reflectivity history (center left),

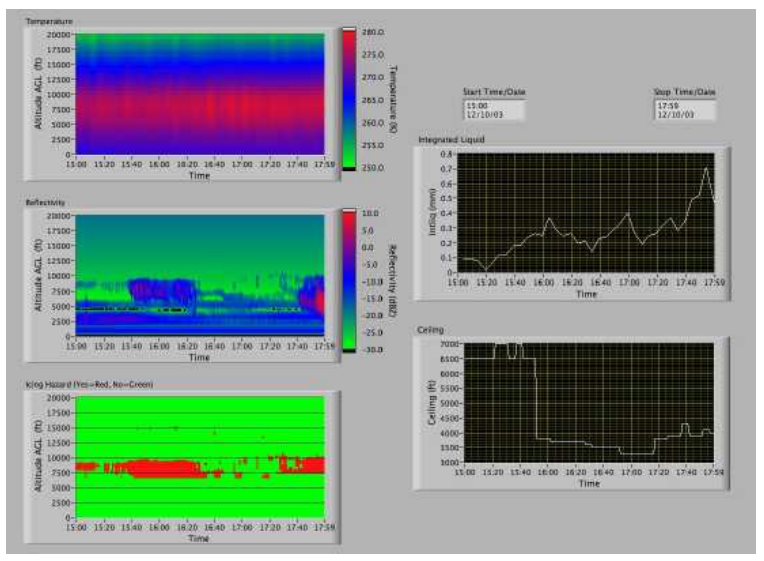

Figure 12. NIRSS Gen 1 software interface. integrated cloud liquid (liquid water path) history (top right), ceiling history (bottom right), and the resultant icing hazard profile history (bottom left).

As with the radiometer data above, comparisons were made between the output from this system and aircraft data for all cases when the NASA Twin Otter performed descending spirals over the Mirabel site. Comparisons were made for the same dates reviewed above, 11 November 2003 between 1630 UTC and 1657 UTC, 18 November 2003 between 1233 UTC and 1246 UTC, 25 November 2003 between 1809 UTC and 1830 UTC, 10 December 2003 between 1617 UTC and 1637 UTC, and on 10 December 2003 between 1720 UTC and 1732 UTC.

For the purposes of the comparisons shown here, the Above Ground Level (AGL) altitude that the Remote Sensing System would normally output was converted to Pressure Altitude. During the test, the surface-level pressure altitude was monitored and recorded using a standard aircraft altimeter fixed to the research ground site. This altimeter was set to 29.92 inches of mercury (1013.2 mb), which is the standard 
setting for the research pressure system in the NASA aircraft. During post-processing, the ground site altimeter reading was added to the AGL values, thus providing a comparable altitude for the aircraft data.

Three plots are shown for each comparison between flight and remotely sensed data. For each of these plots the aircraft measured parameter is compared to a remotely sensed (R-S) value from the beginning of the maneuver (value 1) and the end of the maneuver (value 2). The top plot shows the comparison between flight measured LWC and the value derived from the remote sensed (R-S) measurements, as described above. On this figure, the aircraft term, labeled KLWC, is the zero-corrected output of the CSIRO-King LWC probe. The center plot shows the comparison between aircraft measured static outside air temperature (Ts) and the air temperature profile calculated from the TP/WVP 3000 radiometer measurements. The bottom plot shows the comparison between aircraft measured ice detection and the icing hazard term derived from the remotely sensed measurements, as described above. The aircraft term is the voltage (divided by ten) output of the Rosemount Ice Detector.

It should be noted that the output of the remote sensing system contains a mixture of imperial and SI units. This mixture of units is caused by the desire to conform to the standard units of the United States aviation community.

\section{Data comparison for 11November 2003, 1630-1657 UTC}

Flight records noted that there was no ice accretion during this spiral maneuver, with only ice crystals present above the freezing level.

The comparison between aircraft-measured values and remotely-sensed and derived values is shown in Fig. 13. Both flight and remotely-sensed values of LWC are negligible. The air temperature measurements agree within $3{ }^{\circ} \mathrm{C}$.

This case demonstrates that the remote sensing system can distinguish between liquid and ice content, and that it correctly determined that there was no icing hazard present.

Data comparison for 18 November 2003, $\underline{1233-1246 \text { UTC }}$

The flight records noted that there was no ice accretion during this spiral maneuver, with a single cloud layer and clear sky above. In this case there was liquid water present, but the temperatures were above freezing throughout the cloud layer.

Comparison between aircraft-measured values and remotely-sensed and derived values is shown in Fig. 14. Likely because of the temperature inversions present, the temperature agreement was not as good for this case compared to the one shown in Fig. 13. In this case the temperature varied by up to $5{ }^{\circ} \mathrm{C}$. Such dramatic temperature discrepancies can easily be the difference between icing and non-icing environments. Despite this fact, the remote sensing system did
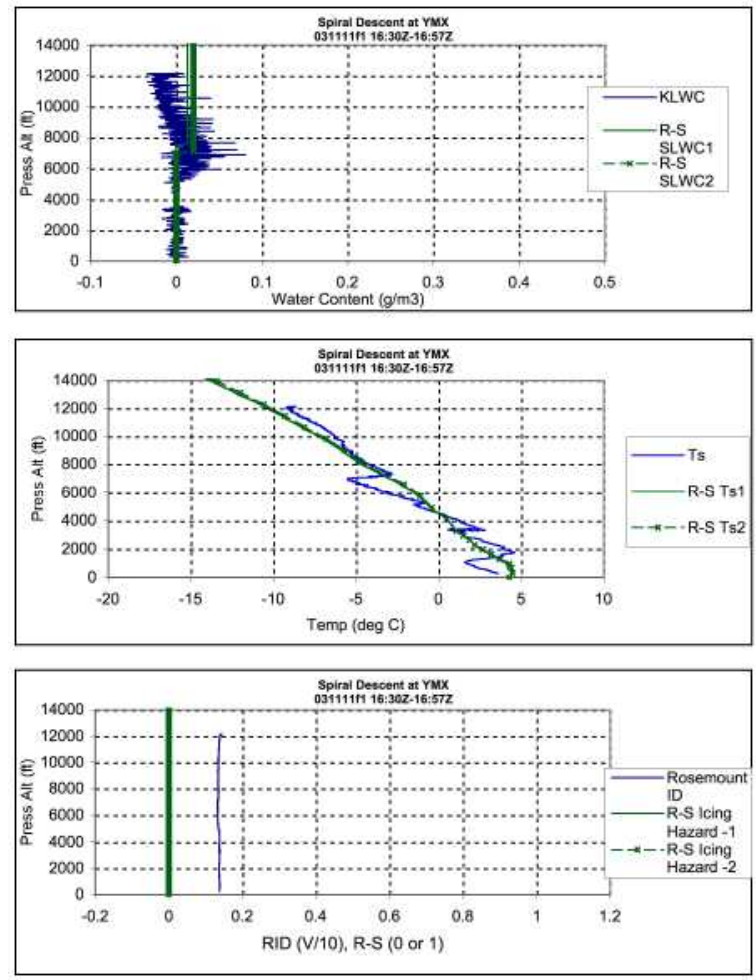

Figure 13. Comparison of NIRSS and Twin Otter for 11 November 2003 flight. 
correctly determine that the liquid water was not supercooled, and that there was no icing hazard present in this case.

Data comparison for 25 November 2003, $\underline{1809-1830 \text { UTC }}$

Flight records noted that there was light rime icing during this spiral maneuver with ice crystals precipitating from the cloud and clear sky above the single cloud layer.

Comparison between aircraft-measured values and remotely-sensed and derived values is shown in Fig. 15. Again, the remotely measured temperature profile is smoothed through the temperature inversion, so that disagreement as great as $6{ }^{\circ} \mathrm{C}$ existed. However, despite the temperature errors, the remote sensing system correctly bounded the region of supercooled liquid water content leading to a conservative flagging of the altitudes with an icing hazard.

Data comparison for 10 December 2003, 1617-1637 UTC (flight \#1)

Flight records noted three liquid cloud layers, with the upper one colder than $0{ }^{\circ} \mathrm{C}$ and producing a light clear ice accretion; the sky was clear above these three layers and clear below the layers with no precipitation.

Comparison between aircraft-measured values and remotely-sensed and derived values is shown in Fig. 16. Because of the sharp temperature inversion near 2,000 ft $(610 \mathrm{~m})$ the disagreement in temperature peaked at that point at $5{ }^{\circ} \mathrm{C}$. The determination of supercooled liquid water content and the corresponding identification of hazardous icing conditions agrees well with the flight measurements and flight log, although the altitude range of diagnosed icing hazard is somewhat conservative.

Data comparison for 10 December 2003, 1720-1732 UTC (flight \#2)

Occurring roughly an hour after the previous case, flight records again noted three liquid cloud layers, with the upper one colder than $0^{\circ} \mathrm{C}$ and producing a light clear ice accretion; the sky was clear above these three
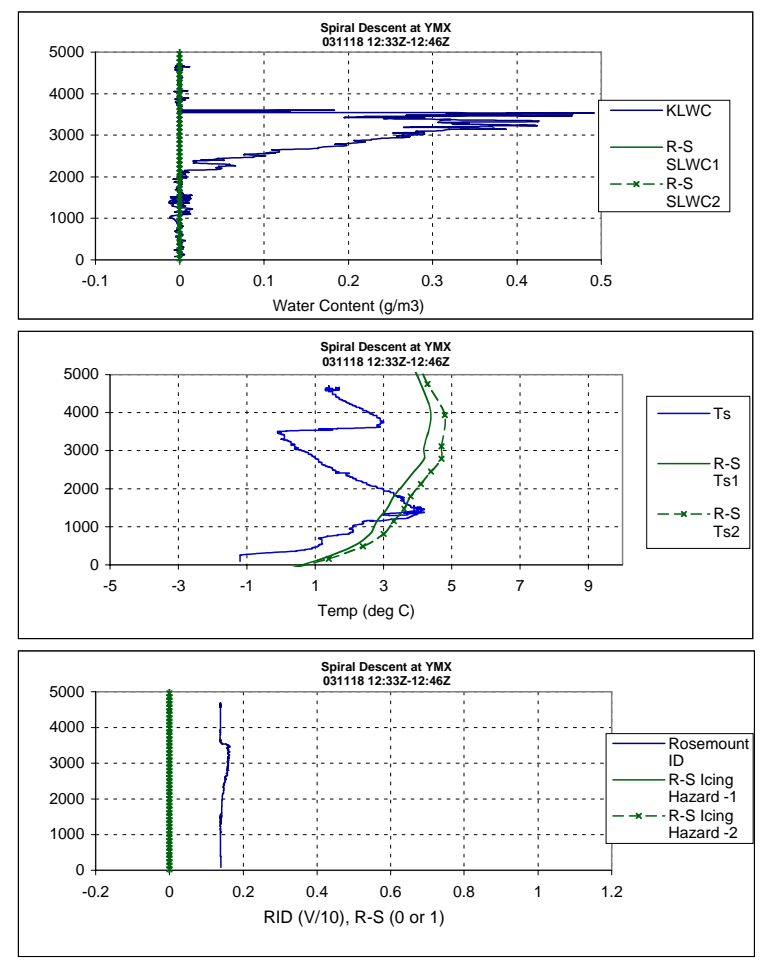

Figure 14. Comparison of NIRSS and Twin Otter for 18 November 2003 flight.
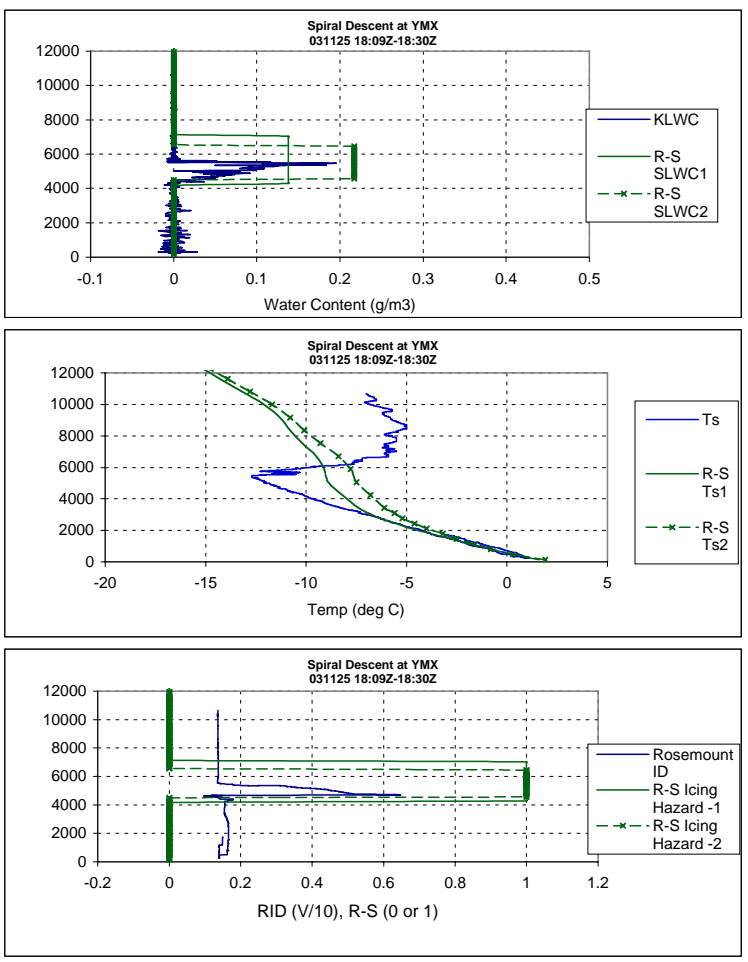

Figure 15. Comparison of NIRSS and Twin Otter for 25 November 2003 flight. 
layers and clear below the layers with no precipitation.

Comparison between aircraft-measured values and remotely-sensed and derived values is shown in Fig. 17. Because of the $8{ }^{\circ} \mathrm{C}$ temperature inversion near the surface, the remotely measured temperature again varies from the aircraft measured values, this time by less than $4{ }^{\circ} \mathrm{C}$. However, since the temperature measurements were accurate in the area of icing conditions, the remote sensing system conservatively bounded the region of supercooled liquid water and identified it as an aircraft hazard.

\section{Concluding Remarks}

Through this review of the measurements made with the NASA Icing Remote Sensing System and the comparison to aircraft measurements, the authors feel that several points have been demonstrated. Most importantly, there is merit in the general pursuit of a ground-based determination of the aircraft icing conditions aloft. The state of the icing environment is measurable. At this point in time, research needs to be directed to optimize these measurement techniques. Microwave radiometry has noteworthy value since it can provide a significant amount of information about the state of the environment in a nearly continuous manner, which is a significant advancement over the limitations of occasional weather balloon and aircraft observations. However, current microwave radiometry does have its shortcomings. Additional effort is required to improve the resolution of radiometer derived temperature and humidity profiles, particularly in inversion situations. Also the improved determination of radiometer derived liquid water profiles requires significant effort. Some of these shortcomings in radiometer measurements may be overcome with the fusion of other data sources. The fusion of radiometer, radar, and lidar data was examined in this effort and shows significant promise. To aid in the development of refined measurement techniques, more comparison aircraft data is required.
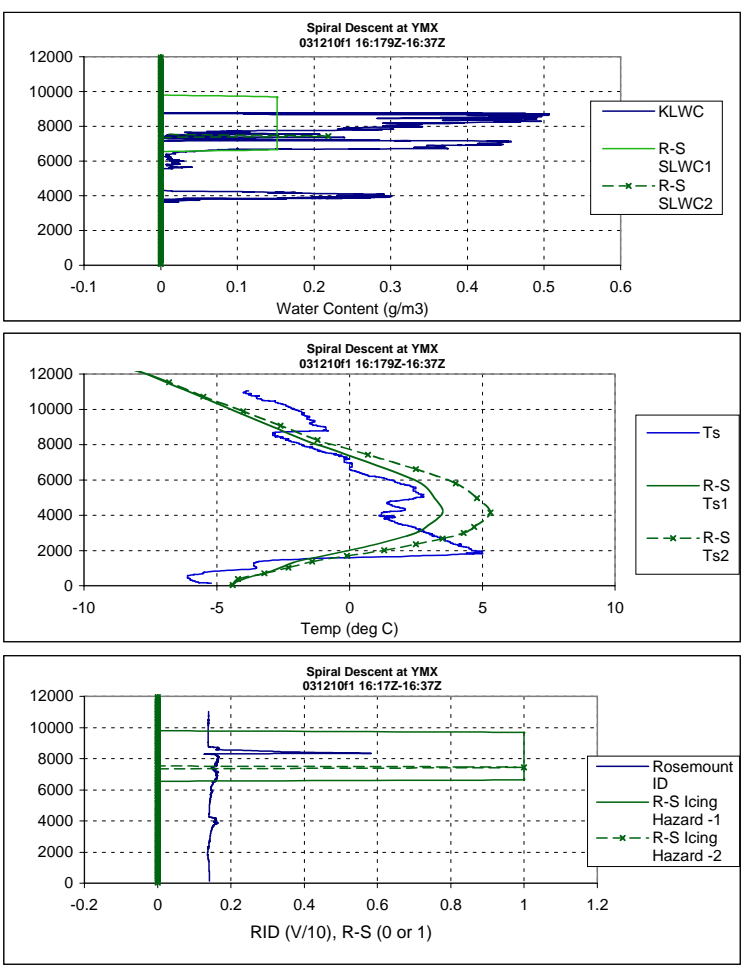

Figure 16. Comparison of NIRSS and Twin Otter for 10 December 2003, flight \#1.
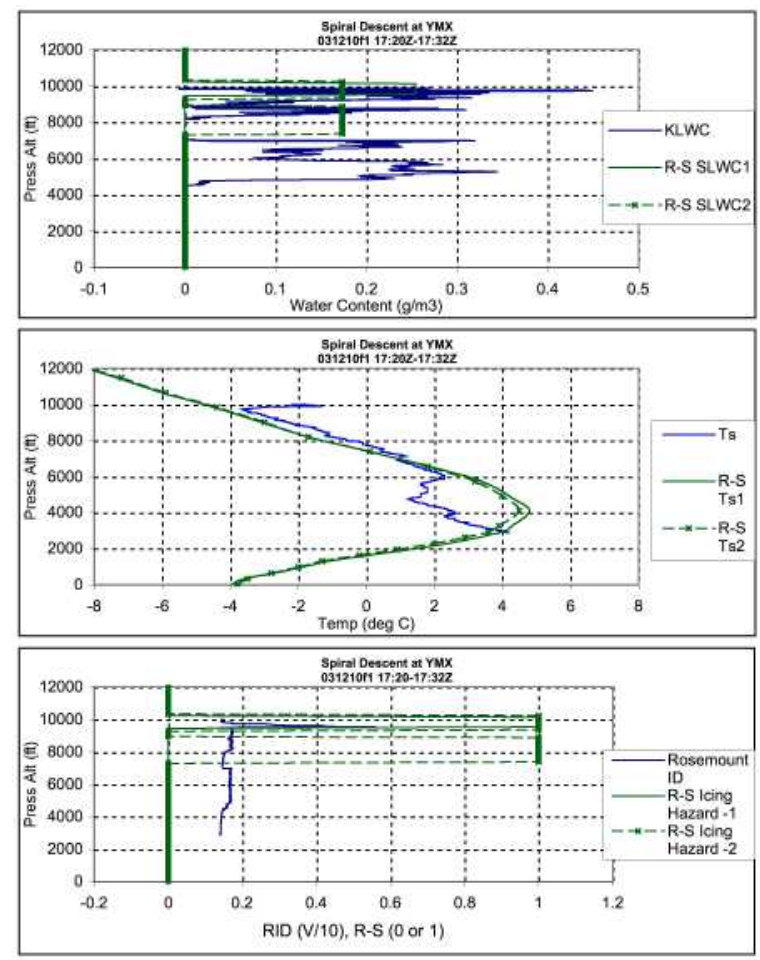

Figure 17. Comparison of NIRSS and Twin Otter for 10 December 2003, flight \#2. 


\section{References}

${ }^{1}$ Reehorst, A.L., Brinker, D.J., Ratvasky, T.P., Ryerson, C.C., and Koenig, G.G., "The NASA Icing Remote Sensing System," paper P6.2-AMS $11^{\text {th }}$ Conference on Aviation, Range, and Aerospace Meteorology, AMS, Hyannis, MA, 2004.

${ }^{2}$ Reehorst, A.L. and Koenig, G.G., "Ground-based icing condition remote sensing system definition,” NASA/TM-2001-211102, 2001.

${ }^{3}$ Strapp, W. “AIRS II Operations Plan,” http://www.airs-icing.org/AIRS_II/AIRS_II.htm, 2003. 


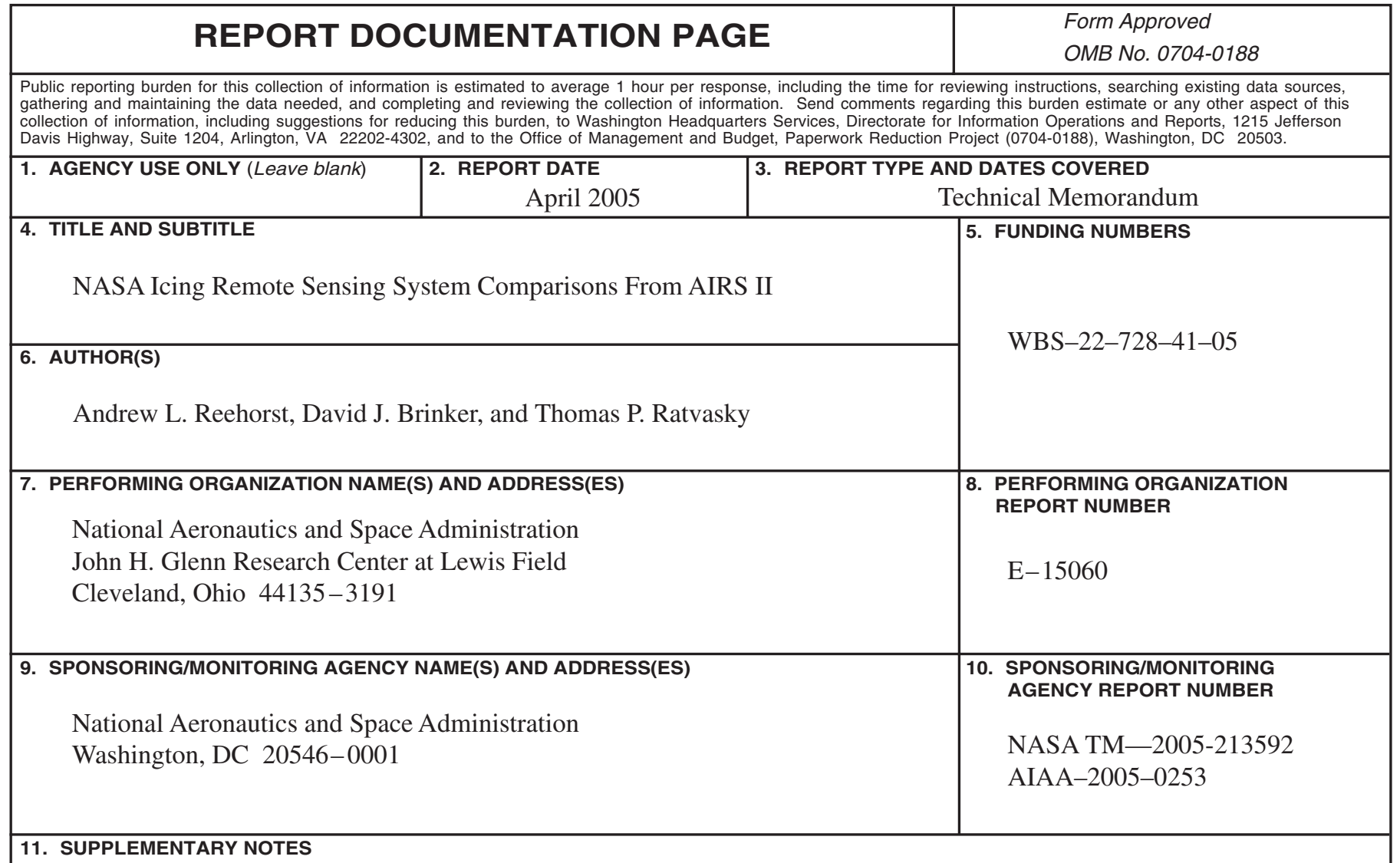

Prepared for the 43rd Aerospace Sciences Meeting and Exhibit sponsored by the American Institute of Aeronautics and Astronautics, Reno, Nevada, January 10-13, 2005. Responsible person, Andrew L. Reehorst, organization code RTI, 216-433-3938.

\begin{tabular}{|l|l|l|l|}
\hline 12a. DISTRIBUTION/AVAILABILITY STATEMENT & 12b. DISTRIBUTION CODE
\end{tabular}

Unclassified - Unlimited

Subject Category: 03

Available electronically at http://gltrs.grc.nasa.gov

This publication is available from the NASA Center for AeroSpace Information, 301-621-0390.

13. ABSTRACT (Maximum 200 words)

NASA has an on-going activity to develop remote sensing technologies for the detection and measurement of icing conditions aloft. A multiple instrument approach is the current emphasis of this activity. Utilizing radar, radiometry, and lidar, a region of supercooled liquid is identified. If the liquid water content (LWC) is sufficiently high, then the region of supercooled liquid cloud is flagged as being an aviation hazard. The instruments utilized for the current effort are an $\mathrm{X}$-band vertical staring radar, a radiometer that measures twelve frequencies between 22 and $59 \mathrm{GHz}$, and a lidar ceilometer. The radar data determine cloud boundaries, the radiometer determines the sub-freezing temperature heights and total liquid water content, and the ceilometer refines the lower cloud boundary. Data is post-processed with a LabVIEW program with a resultant supercooled LWC profile and aircraft hazard identification. Individual remotely sensed measurements gathered during the 2003-2004 Alliance Icing Research Study (AIRS II) were compared to aircraft in-situ measurements. Comparisons between the remote sensing system's fused icing product and in-situ measurements from the research aircraft are reviewed here. While there are areas where improvement can be made, the cases examined indicate that the fused sensor remote sensing technique appears to be a valid approach.

14. SUBJECT TERMS

Aircraft icing; Aviation meteorology; Remote sensing; Multisensor fusion

15. NUMBER OF PAGES

16

16. PRICE CODE

20. LIMITATION OF ABSTRACT

\begin{tabular}{|c|c|c|}
\hline $\begin{array}{c}\text { 17. SECURITY CLASSIFICATION } \\
\text { OF REPORT } \\
\text { Unclassified }\end{array}$ & $\begin{array}{c}\text { 18. SECURITY CLASSIFICATION } \\
\text { OF THIS PAGE } \\
\text { Unclassified }\end{array}$ & $\begin{array}{c}\text { 19. SECURITY CLASSIFICATION } \\
\text { OF ABSTRACT } \\
\text { Unclassified }\end{array}$ \\
\hline
\end{tabular}

NSN 7540-01-280-5500

Standard Form 298 (Rev. 2-89)

Prescribed by ANSI Std. Z39-18 298-102 

